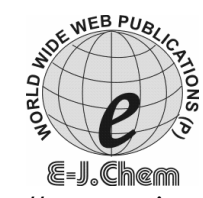

http://www.e-journals.net
ISSN: 0973-4945; CODEN ECJHAO

E-Journal of Chemistry

2009, 6(S1), S41- S46

\title{
Assessment of the Impact of Industrial Effluents on Groundwater Quality in Okhla Industrial Area, New Delhi, India
}

\author{
WEQUAR AHMAD SIDDIQUI and RAJIV RANJAN SHARMA \\ Department of Applied Sciences and Humanities, \\ Faculty of Engineering and Technology. \\ Jamia Millia Islamia (Central University), New Delhi-110025, India. \\ drwasiddique@yahoo.com
}

Received 16 November 2008; Revised 17 March 2009; Accepted 8 April 2009

\begin{abstract}
In the present study physicochemical parameters like $\mathrm{pH}$, hardness, TDS, chloride, sulphate, nitrate, fluoride, DO, COD and conductivity of some important heavy metals such as iron, cobalt, cadmium, lead, mercury, chromium, selenium and arsenic were first analyzed in effluent water of Okhla industrial area phase-II and then groundwater of near by areas. Obtained values of effluent water were compared with ISI standard for effluent water discharge and groundwater values were compared with ISI and WHO drinking water standards. The result shows that discharge of untreated effluents by the industries is leading to contamination of groundwater of the surrounding areas. Lead, mercury, fluoride, TDS, sulphate was above the desirable limit in effluent water (ISI standard for effluent water discharge). Subsequent analysis of groundwater of nearby areas was rated as unacceptable for drinking because of presence of fluoride in all the samples above the desirable limit. Lead, mercury, cadmium, chloride was also detected in many samples.
\end{abstract}

Keywords: Heavy metal analysis, COD, DO, TDS, Physicochemical analysis

\section{Introduction}

It is evident that many parts of the industrial area in India are colonized and are in very close vicinity of the industries and are using groundwater for drinking, cleaning and bathing purposes. In India groundwater is used for domestic and agricultural purposes. Heavy metals are basically present in groundwater but these play an important role in determining the quality of water for drinking purposes ${ }^{2}$. Metals are considered toxins and when they enter the body more than the prescribed limit they start causing harm. In the same way many physicochemical parameters play an important role in determining the quality of water. 
The excesses concentration of these may cause various ill effects ${ }^{4}$. The levels of heavy metals need to be studied in both effluent and groundwater. Present work was carried in the Okhla industrial area phase-II, New Delhi, India in the year 2007. In the close vicinity of this industrial area there is dense population of residents who generally use underground water for most of there domestic purposes.

In this paper physicochemical parameters and some important heavy metals like lead, cadmium, arsenic, chromium, copper, iron, zinc, cobalt, mercury, selenium have been studied in effluent water and subsequently in groundwater of this locality.

\section{Experimental}

The procedure followed for analysis was from APHA $^{5}$. All the samples were collected in polypropylene bottles which were properly washed with $20 \%$ nitric acid and subsequently with deminierialized water. These were subsequently washed with deminierialized water of milli-Q system (ion exchange and filtration processes). Chemicals used in the analysis were of grade 'A', acids, modifiers are of suprapure grade.

Determination of heavy metal was done on atomic absorption spectrophotometer (AAS) furnace technique ${ }^{6,7}$ (Perkin Elmer's AAS-600 with Zeeman correction and L'vov platform), flame AAS technique (AAS-300) and flow injection atomic spectroscopy ${ }^{8}$ (FIAS) attached with AAS-600.

Zinc and Iron analysis was done on flame method (AAS-300, PerkinElmer) Mercury and arsenic analysis was carried out by the flow injection atomic spectroscopy (FIAS) attached with AAS $-600^{8}$. The rest of the elements were analyzed by directly on AAS- 600 .

The samples of effluent and groundwater were collected from different locations of the Okhla industrial area phase-II. The samples collection bottles were uniquely labeled before collection. Groundwater samples were labeled starting with alphabet G (G-1 to G-10). The industrial effluent water was labeled starting with alphabet E (E-1 to E-10). The analysis of the sample was carried immediately after the collection of the samples. Sample collection locations are listed in Table 1 shown below.

Table 1. Sample collection locations.

\begin{tabular}{cclc}
\hline \multicolumn{2}{c}{ Effluent water, Okhla phase-II } & \multicolumn{2}{c}{ Groundwater, Near by areas } \\
\hline \multicolumn{1}{c}{ Site } & Sample No. & \multicolumn{1}{c}{ Site } & Sample No \\
\hline X-Block & E-1 & Sanjay Colony & G-1 \\
A-Block & E-2 & Sarita Vihar & G-2 \\
B-Block & E-3 & Madanpurkhadar & G-3 \\
C-Block & E-4 & Tughlakabad & G-4 \\
D-Block & E-5 & Container depot & G-5 \\
E-Block & E-6 & Josala & G-6 \\
F-Block & E-7 & Tehkhand & G-7 \\
G-Block & E-8 & Sukhdev Vihar & G-8 \\
H-Block & E-9 & Govindpuri & G-9 \\
I-Block & E-10 & Kalka Depot & G-10 \\
\hline
\end{tabular}

\section{Results and Discussion}

Results show considerable variation in the amount of heavy metals and physicochemical parameters for different industrial effluents samples. The results are summarized in Table $2 \&$ 3. Thee results are compared with standards for effluent water discharge (12) IS10500. 
The results of heavy metal determinations in effluent water sample (Table 2) exhibit that the amount of $\mathrm{Cu}, \mathrm{Se}, \mathrm{Zn}$ and As are below the desirable limit in all the effluent water samples. However the amount of $\mathrm{Fe}$ is found more than prescribed desirable limit for sample number E2 while for rest of the effluent samples it is less than the desirable limit. Though the level of $\mathrm{Cd}$ is above the desirable limit in samples $\mathrm{E} 1$ and $\mathrm{E} 2$ but for the rest of the effluent samples it is below the desirable limit. $\mathrm{Pb}$ is above the desirable limit in samples E1, E2 and E3 while it is almost equal to the desirable limit in sample E6. The amount of $\mathrm{Cr}$ is above the desirable limit in sample E2 but it is found to be considerably low in other effluent water samples. The level of $\mathrm{Hg}$ is above desirable limit in samples E1 and E2.

Table 2. The results of heavy metal determinations in effluent water sample.

\begin{tabular}{cclcccccccccc}
\hline S.No. & $\begin{array}{c}\text { Type of } \\
\text { metal }\end{array}$ & $\begin{array}{c}\text { Desirable } \\
\text { limit, } \mu \mathrm{g} / \mathrm{L}\end{array}$ & E-1 & E-2 & E-3 & E-4 & E-5 & E-6 & E-7 & E-8 & E-9 & E-10 \\
\hline 1 & $\mathrm{Fe}$ & 3000 & 2500 & 3200 & 731 & 675 & 654 & 700 & 2500 & 2430 & 2431 & 2600 \\
2 & $\mathrm{Cu}$ & 3000 & 2000 & 1500 & 951 & 1200 & 2500 & 1500 & 2500 & 2500 & 2450 & 875 \\
3 & $\mathrm{Co}$ & - & 2.5 & 3.5 & 21.0 & 10.0 & 10.7 & 5.4 & 4.5 & 6.5 & 3.2 & 2.5 \\
4 & $\mathrm{Cd}$ & 2000 & 2500 & 2100 & 1900 & 500 & 245 & 521 & 1200 & 551 & 254 & 260 \\
5 & $\mathrm{~Pb}$ & 100 & 145 & 135 & 120 & 45 & 65 & 101 & 25.4 & 26.4 & 34.5 & 30.6 \\
6 & $\mathrm{Hg}$ & 10 & 11.5 & 15.4 & 4.5 & 6.5 & 7.0 & 8.5 & 8.5 & 7.4 & 5.5 & 5.4 \\
7 & $\mathrm{Zn}$ & 5000 & 4500 & 1500 & 5451 & 1545 & 4950 & 5125 & 4500 & 4120 & 3998 & 2514 \\
8 & $\mathrm{Cr}(\mathrm{Total})$ & 2000 & 1500 & 2500 & 500 & 74.0 & 55 & 65 & 514 & 345 & 650 & 412 \\
9 & $\mathrm{Se}$ & 50 & 45 & 25 & 15 & 19 & 45 & 25 & 15 & 25 & 14.5 & 15.3 \\
10 & $\mathrm{As}$ & 200 & 145 & 45 & 35 & 25 & 17 & 45 & 10.4 & 11.6 & 10.7 & 12.0 \\
\hline
\end{tabular}

The results of physicochemical studies for the same effluent water samples shown in Table 3. There is a slight variation in the $\mathrm{pH}$ of these samples which ranges from 5.9-8 and is well within the desirable limit. The desirable limits of total hardness, T.D.S., chloride, nitrate, DO, conductivity is not established for effluent waste water but its effect on groundwater has been studied. The amount of sulphate in the effluent water is above the desirable limit. The range of fluoride is varying from $2.4-22 \mathrm{mg} / \mathrm{L}$ which is above the desirable limit. The value of COD is well within the prescribed desirable limit.

Table 3. The results of physicochemical studies for the effluent water samples.

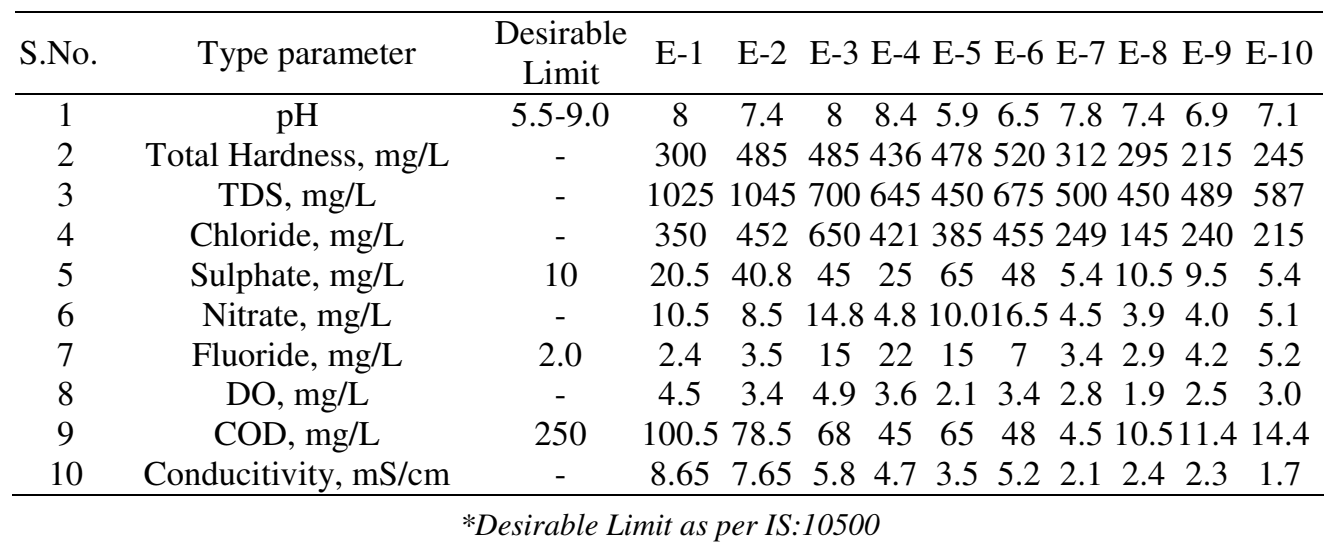


The standard followed for groundwater is IS 10500 and 'WHO' drinking water standard. The groundwater results also show a considerable variation in the amount of heavy metals and physicochemical parameters. As expected results show that all the values of $\mathrm{Fe}, \mathrm{Cu}, \mathrm{Zn}, \mathrm{Se}$ and As (Table 4) are within the desirable limit but for sample G1 and G2 value of cadmium are above desirable limit however for rest of the samples the values are with in the desirable limit. $\mathrm{Pb}$ is above desirable limit in sample G1 and G2 while for rest of the samples values are well within the desirable range. Mercury showed borderline values in samples G1, G2, and G6 while other values are well with in the desirable range. Two values of chromium are above desirable limit in G1 and G2 sample but it is normal in rest of the samples.

Table 4. The results of heavy metal determinations in groundwater samples.

\begin{tabular}{ccccccccccccc}
\hline S.No & $\begin{array}{c}\text { Metal } \\
\text { type }\end{array}$ & $\begin{array}{c}\text { Desirable } \\
\text { limit, } \mu \mathrm{g} / \mathrm{L}\end{array}$ & G-1 & G-2 & G-3 & G-4 & G-5 & G-6 & G-7 & G-8 & G-9 & G-10 \\
\hline 1 & $\mathrm{Fe}$ & 300 & 200.3 & 250.1 & 200.2 & 154.4 & 145.4 & 210.4 & 149.8 & 245.6 & 278.0 & 265 \\
2 & $\mathrm{Cu}$ & 50 & 36.5 & 48.5 & 10.5 & 5.4 & 8.8 & 5.4 & 10.5 & 5.5 & 4.5 & 6.8 \\
3 & $\mathrm{Co}$ & - & 15 & 5 & 5.6 & 4.3 & 2.6 & 0.5 & 0.7 & 0.8 & 1.1 & 0.9 \\
4 & $\mathrm{Cd}$ & 10 & 15.3 & 10.4 & 8.7 & 6.6 & 6.5 & 4.5 & 3.5 & 4.2 & 3.8 & 4.2 \\
5 & $\mathrm{~Pb}$ & 50 & 55.4 & 53.2 & 49.8 & 25.6 & 45.5 & 38.6 & 10.4 & 21.2 & 15.4 & 11.7 \\
6 & $\mathrm{Hg}$ & 1.0 & 1.2 & 1.1 & 0.9 & 0.8 & 0.9 & 1.3 & 0.8 & 0.7 & 0.5 & 0.7 \\
7 & $\mathrm{Zn}$ & 5000 & 2012 & 800.6 & 3067 & 2800 & 500.6 & 899.7 & 1500 & 2540 & 2321 & 2584 \\
8 & $\mathrm{Cr}($ Total $)$ & 50 & 55.2 & 50.4 & 30 & 34.7 & 54.4 & 34.2 & 10.5 & 4.2 & 5.3 & 4.2 \\
9 & $\mathrm{Se}$ & 10 & 5.7 & 8.5 & 8.9 & 7.6 & 5.8 & 9.7 & 2.5 & 2.1 & 1.9 & 1.5 \\
10 & $\mathrm{As}$ & 50 & 12.4 & 9.6 & 10.4 & 8.4 & 7.8 & 14.2 & 7.8 & 4.5 & 5.6 & 5.0 \\
\hline
\end{tabular}

*Desirable Limit as per IS:10500**WHO Standard Value

Values of $\mathrm{pH}$, TDS, Total Hardness, and nitrate are with in the desirable limit Table 5. Chloride is above desirable limit in sample G1, G3, G5 and G6 while it is normal in other samples. Sulphate is high in sample G1, G3, G4 and G5 sample. The value of fluoride has varied from 1-3.1, four sample of sulphate is on borderline side and six are well above desirable limit. Two values of COD are on borderline (G1, G3 and G6) and rests are well within desirable range. DO is low only in one sample G6 and is normal in all other samples. Conductivity has shown variation $0.28-1.7$ only one sample is above desirable range.

Table 5. The results of physicochemical studies for the groundwater samples.

\begin{tabular}{cccccccccccccc}
\hline \multirow{2}{*}{ S.No } & Metal type & $\begin{array}{c}\text { Desirable } \\
\text { limit }\end{array}$ & G-1 & G-2 & G-3 & G-4 & G-5 & G-6 & G-7 & G-8 & G-9 & G-10 \\
\hline 1 & pH & $6.5-8.5$ & 6.8 & 7.0 & 6.7 & 7.0 & 7.8 & 6.8 & 7.1 & 6.9 & 7.0 & 7.1 \\
2 & Total hardness, mg/L & 300 & 120 & 95 & 200 & 145 & 250 & 70.0 & 100.2 & 75.2 & 65.2 & 60.0 \\
3 & TDS, mg/L & 500 & 245 & 180 & 210 & 100.2 & 485 & 385 & 118 & 289 & 154 & 285 \\
4 & Chlorides, mg/L & 250 & 330 & 248 & 250 & 434 & 268 & 398 & 150 & 138 & 145 & 124 \\
5 & Sulphate, mg/L & 200 & 350 & 150 & 330 & 274 & 434 & 256 & 140 & 139 & 124 & 125 \\
6 & Nitrate, mg/L & 45 & 8.8 & 6.5 & 8.5 & 3.0 & 2.4 & 4.5 & 8.9 & 4.7 & 5.0 & 4.8 \\
7 & Fluoride, mg/L & 1.0 & 1.4 & 1.1 & 1.5 & 1.4 & 1.0 & 1.4 & 1.5 & 1.0 & 2.7 & 3.1 \\
8 & DO, mg/L & $>5$ & 8.0 & 8.8 & 7.8 & 9.5 & 5.8 & 4.0 & 7.8 & 10.4 & 9.9 & 7.5 \\
9 & COD, mg/L & $10^{* *}$ & 10.0 & 9.0 & 10.0 & 8.0 & 5.3 & 13 & 7.8 & 6.5 & 4.5 & 4.8 \\
10 & Conducitivity, & $1.400^{* *}$ & 0.37 & 0.28 & 0.570 .485 & 1.7 & 0.578 & 0.40 & 0.29 & 0.31 & 0.39 \\
\hline
\end{tabular}

*Desirable limit as per IS:10500**WHO Standard value 
The high values of heavy metals and physicochemical parameters have severe health consequences and these are discussed independently below. Among the studied metals listed in Table 4. Iron, copper, cobalt, zinc, selenium are essential metals and they are required for the body. Copper is essential component of several enzymes. It is essential for utilization of iron. Cobalt is essential as a component of vitamin $\mathrm{B}_{12}$ required for production of red blood cells and prevention of pernicious anemia. Deficiency of selenium leads to cardiomyopathy in mammals including humans. Zinc is a nutritionally essential metal, and its deficiency results in severe health consequences ${ }^{3}$. Chromium is important in glucose and cholesterol metabolism ${ }^{2}$. Iron is an essential nutrient for erythropoiesis 9 .

In the present study, result shows that the concentrations of iron, copper, cobalt, zinc, selenium and chromium are within desirable limits in all the samples so it is not going to cause ill effects on the near by population. But these metals become toxic when they exceed the normal range. The normal range in adult male for iron in serum is $65-175 \mu \mathrm{g} / \mathrm{dL}$ for copper it is $70-140 \mu \mathrm{g} / \mathrm{L}$, for cobalt is $0.11-0.45 \mu \mathrm{g} / \mathrm{L}$, for zinc it is $70-120 \mu \mathrm{g} / \mathrm{dL}$, for selenium it is $46-143 \mu \mathrm{g} / \mathrm{L}$ and chromium ${ }^{10}$ is ranging $<0.05-0.5 \mu \mathrm{g} / \mathrm{L}$.

The second group of heavy metals in the present study is cadmium, lead, mercury and arsenic and cobalt. These elements are not at all required by the body so it may cause harmful effects if there concentration increases in the body above the prescribed limit. In the present study lead, mercury, cadmium and mercury were found in some groundwater there it may cause ill effects on the population consuming this groundwater.

The normal ranges prescribed for cadmium in whole blood is $0.3-1.2 \mu \mathrm{g} / \mathrm{L}$ for non smokers and 0.6-3.9 $\mu \mathrm{g} / \mathrm{L}$ for smokers. For adult the normal range for lead in whole blood is $<25 \mu \mathrm{g} / \mathrm{dL}$. The normal range for mercury in whole blood is $0.6-59 \mu \mathrm{g} / \mathrm{L}$ and for arsenic the normal reference range ${ }^{10}$ is $2-23 \mu \mathrm{g} / \mathrm{L}$

Acute effects of lead are inattention, hallucinations; delusions, poor memory, and irritability are symptoms of acute intoxication. Lead absorption in children may affect there development and also results in bone stores of lead. It is associated with behavioral effects, nephropathy, and plumbism. Primary target organs of mercury toxicity are nervous system and kidneys ${ }^{3}$. Exposure to elemental mercury is associated with both sensory and motor nerve conduction abnormalities. Mercury poisoning is also associated with erethism, eye disease, skin disease (erythema, itching, papules, and pustules) ${ }^{3}$.

The principle long-term effects of low level exposure to cadmium are chronic obstructive pulmonary disease and emphysema and chronic renal tubular disease. Ingestion of high concentration of cadmium leads to nausea, vomiting, and abdominal pain ${ }^{3 .}$ When arsenic is ingested in large amounts leads to fever, anorexia, hepatomegaly, melanosis, and cardiac arrhythmia and even death ${ }^{3}$.

Metals differ from other toxic substances in way that they are neither created nor destroyed by humans ${ }^{3}$. The conceptual boundaries of what is regarded as the toxicology of metals continue to broaden. Historically, metal toxicology largely concerned acute or overt effects, such as abdominal colic from lead toxicity, or bloody diarrhea and suppression of urine formation from ingestion of corrosive (mercury) sublimate. These metals when enter the body and when their levels cross certain levels they start producing effects and cause ill health.

The $\mathrm{pH}$ values are with in the range as prescribed by IS: 10500, and WHO. Total hardness and total dissolved solids are well with in the desirable range. The elevated values of chloride may cause change in the taste of water, corrosion and palatability are also 
effected. Elevated level of sulphate causes gastro intentional irritation when magnesium and sodium are present. The upper range of fluoride causes fluorosis and effects bone and teeth ${ }^{11}$.

\section{Conclusion}

The groundwater of the studied area near the Okhla industrial area phase-II has been found to be unfit for drinking because fluoride has been detected in all samples above desirable limit. Lead, mercury, chromium, chloride and sulphate has also been detected few samples (Table $4 \& 5$ ). People from that area should drink only treated water. But subsequent review and checking of water should be taken care.

The industry should discharge there effluent water only after proper treatment. Blood, urine hair are the most accessible tissues in which to measure an exposure or dose, as they are some times referred to as indicator tissue.

\section{References}

1. Narendra Singh Bhandri and Kapil Nayal, E Journal of Chemistry, 2008, 5(2), 342-346.

2. Wequar Ahmad Siddiqi and Javed Hassan, Current World Environment, 2006, 1(2), 145.

3. Curtis D Klaassen, Casarett \& Doull's Toxicology, The basic science of poisons, $5^{\text {th }}$, International Edition, McGraw Hill, Health profession division, USA, 1996, 691-721.

4. Mayur C Shah, Prateek G Shilpkar and Praddip B Acharaya, E Journal of Chemistry, 2008, 5(3), 437-441.

5. APHA, Standard methods for the examinations of water and waste waters, $18^{\text {th }}$ Ed., American public health association, Washington, 1989.

6. Perkin Elmer's, Analyst 600 user guide, February 1998.

7. Perkin Elmer's Techniques and recommended conditions, The THGA Graphite Furnace, Release 1.2, August 1995.

8. Perkin Elmer's FIAS, Flow Injection System, Release 1.4, September 1993.

9. Raymond D Harbision, Hamilton and Hardy's, 'Industrial Toxicology,' Mosby, Mosby -Year Book, Inc.,West line Industrial Drive's.Louis, Missouri-63146, $5^{\text {th }}$ Edn., 1830.

10. Norbert W Tietz, Clinical Guide to Laboratory Tests, A division of Harcourt Brace and company, The Curtis Center, Independence Square West, Philadelphia, Pennsylvania, 19106, $3^{\text {rd }}$ Edn., 2000.

11. Arunabh Mishra and Vasistha Bhat, E Journal of Chemistry, 2008, 5(3), 487-492.

12. General Standards for Discharge of Environmental Pollutants, IS 10500.

13. Drinking water specification, 1992 (Reaffirmed 1993): IS: 10500.

14. World Health Organization, Guidelines for drinking water quality-I, recommendations Geneva, WHO, $2^{\text {nd }}$ Ed., 1993.

15. Tasalav D L, Atomic Absorption in occupational and environmental health practice, 'CRC' Press, U.S Inc., 1995, 3. 


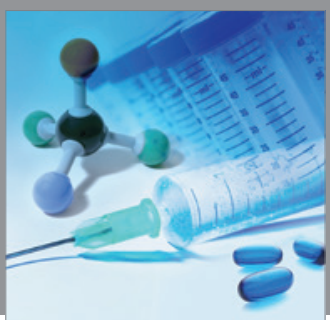

International Journal of

Medicinal Chemistry

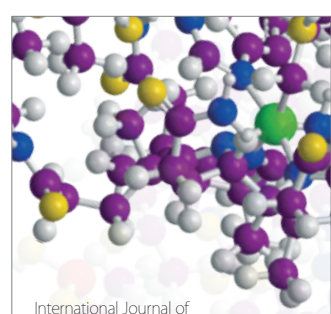

Carbohydrate Chemistry

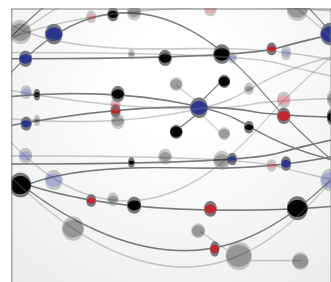

The Scientific World Journal
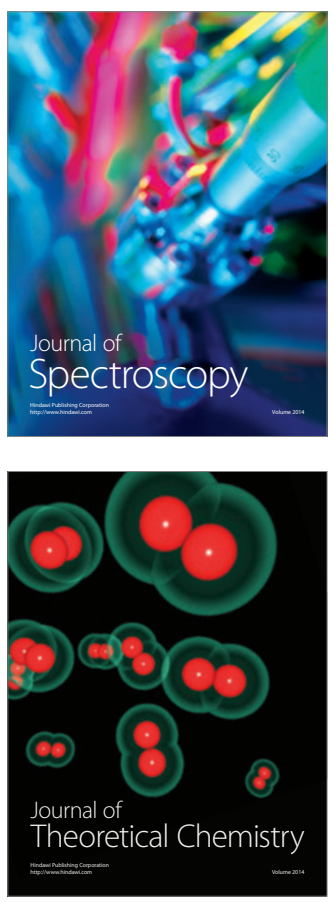
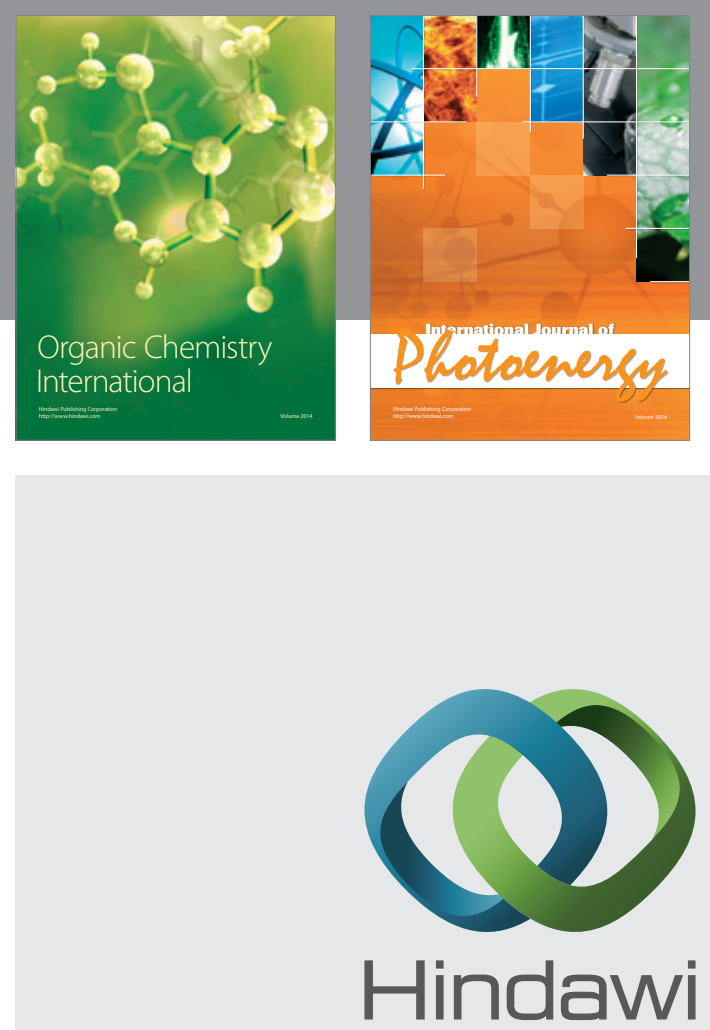

Submit your manuscripts at

http://www.hindawi.com
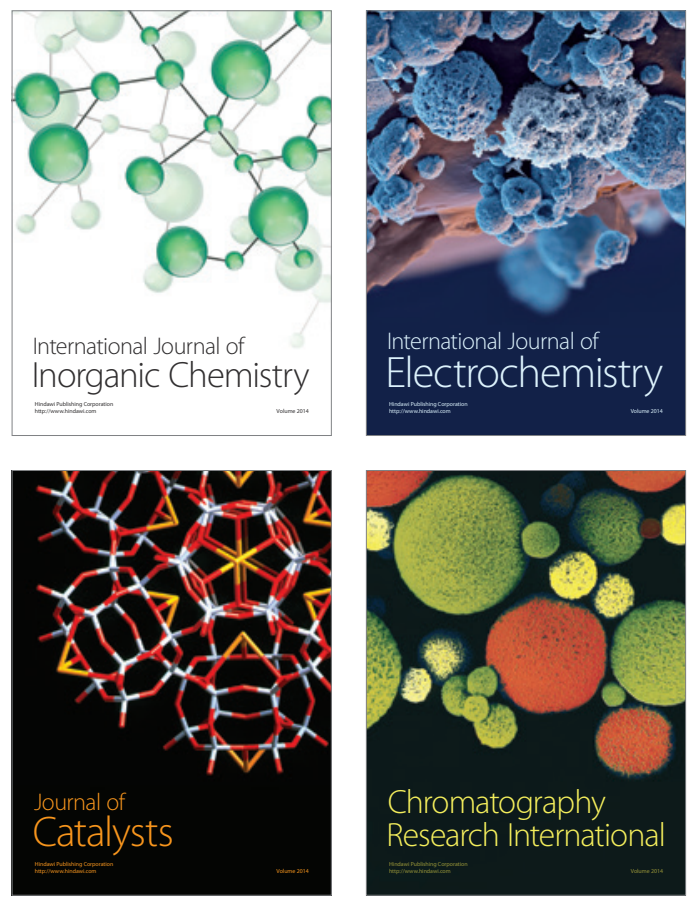
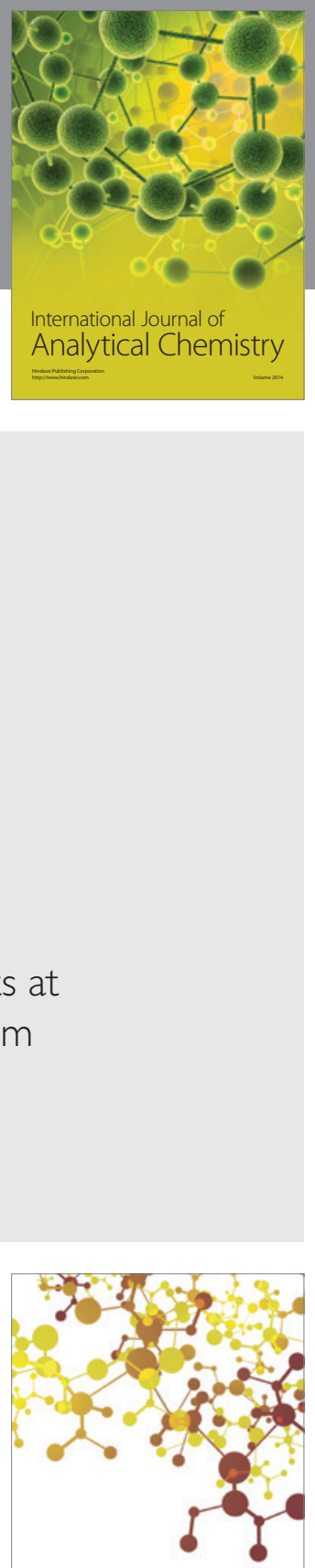

Journal of

Applied Chemistry
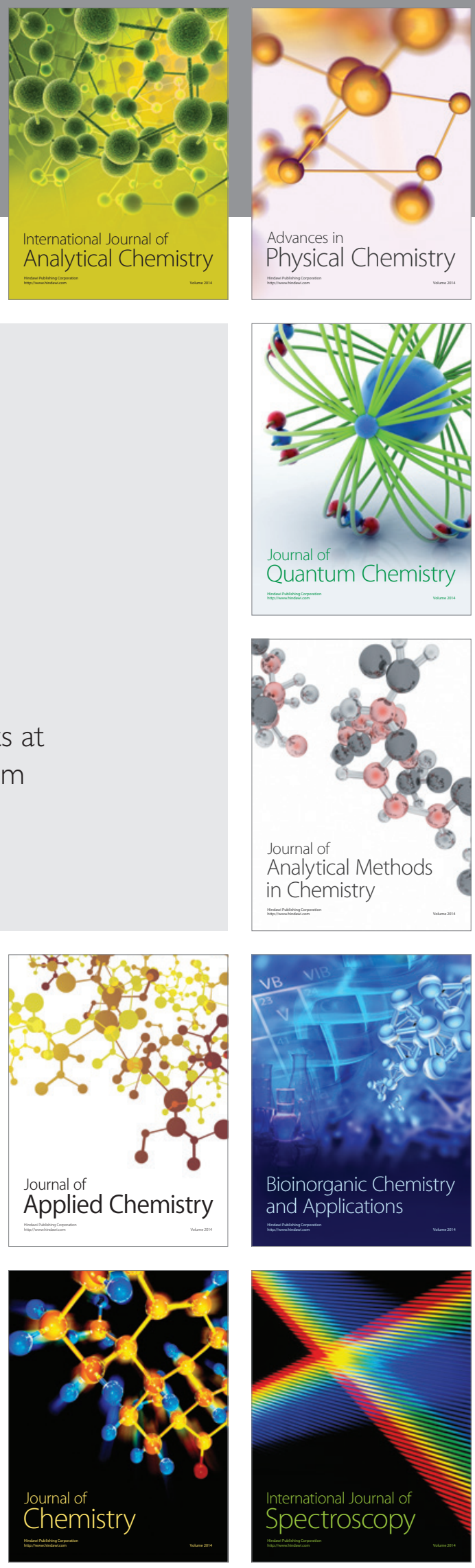